\title{
¿Es consistente una semántica del hablar desde los presupuestos teóricos del estructuralismo?*
}

\author{
Is semantics of speech consistent with \\ structural linguistic theory?
}

\section{Miguel Rosso CARRASCO}

Grupo de investigación "Semaínein"

Instituto Universitario de Investigación en

Lingüística Aplicada

Área de Lingüística General

Departamento de Filología

Facultad de Filosofía y Letras

Universidad de Cádiz

Avda. Gómez Ulla, nº 1

11003 Cádiz-España

miguel.rosso@uca.es

Resumen: Delimitando conceptualmente los términos semántica del hablar y estructuralismo, este trabajo inserta la problemática de la semántica del hablar dentro del marco teórico de Eugenio Coseriu. En dicho marco, esta semántica recogería aspectos no incluidos dentro del nivel particular del lenguaje. Se constata, pues, que carece de una asignación metodológica para el nivel universal. Por ello, se establece la hipótesis de que se debe a la imposibilidad del estructuralismo para llevarlo a cabo consistentemente. Para evaluarla, se exponen los argumentos al respecto de Paul Ricœur, si bien se critica que no tuviese en cuenta los esfuerzos del estructuralismo por superar su limitación de ocuparse solo de los aspectos sistemáticos de las lenguas. Luego, se elabora una crítica a las observaciones de Coseriu a la semántica cognitiva. Se concluye que la semántica del hablar sí es inconsistente con los principios del estructuralismo.

Palabras clave: Estructuralismo. Semántica del hablar. Semántica cognitiva. Sentido. Referencia.

* Este artículo se inserta dentro del proyecto denominado "Comunicación Especializada y Terminografía: Usos Terminológicos Relacionados con los Contenidos y Perspectivas Actuales de la Semántica Léxica" (FFI2014-54609-P), en el marco del Plan Estatal de Investigación Científica y Técnica y de Innovación 2013-2016 de la Secretaría de Estado de Investigación, Desarrollo e Innovación. Aprovecho para agradecer las sugerentes y valiosas observaciones que su investigador principal (Pf. Dr. Miguel Casas) realizó a un borrador preliminar y reconozco igualmente la deuda de este trabajo con el enfoque y los resultados de la investigadora María Dolores Muñoz Núñez. Reconocimiento, en ambos casos, que los exime de las posibles deficiencias que puedan advertirse en este capítulo. 
Abstract: The paper's intention is a programmatic one. After presenting several definitions for the terms semantics of speech and structuralism, the topic is discussed with regard to Coseriu's theoretical framework. After confirming that there is not a methodological assignment within the universal level, I establish the hypothesis that it is due to the impossibility of structuralism for consistently carrying it out. For this purpose, I expound some arguments from Ricœur, criticizing however that he did not take into account the efforts of structuralism to overcome these limitations. Briefly developing several methodological changes to structuralism, I critically comment on some of Coseriu's remarks on cognitive semantics. This allows a better understanding of the relation between the semantics of language and the semantics of speech. Finally, I propose several ways to methodologically develop the semantics of speech.

Keywords: Structuralism. Semantics of speech. Cognitive semantics. Sense. Reference.

\section{INTRODUCCIÓN}

ste artículo se presenta como un intento, a partir de ciertos autores clásicos, de responder a una pregunta: ¿es consistente una semántica del hablar desde los presupuestos teóricos del estructuralismo? Ello presupone, en primer lugar, considerar que el diálogo con los clásicos es y debe ser siempre posible, no tanto en el plano de problemas concretos, donde sus soluciones pueden quedar parcialmente obsoletas, sino en la perspectiva amplia, en su visión general, en su estilo y en su forma idiosincrásica de pensamiento, aspectos que permanecen perennes; por otro, presupone que toda actividad intelectual parte, como sostenía Popper (213-17), de la formulación de problemas. La exposición siempre es gratuita y falta de meta si no permite resolverlos. La formulación de problemas, además, permite proponer, una vez solventados, nuevas etapas en la investigación.

En lo que respecta específicamente a la respuesta a esta pregunta, se ha realizado una reconstrucción parcial del pensamiento de dos autores que, en sentido estricto, no se pronuncian sobre estas cuestiones. Por tanto, es necesario entender que este artículo no es, sin más, la mera exposición acrítica de cómo dos autores, concretamente Coseriu y Ricœur, se han posicionado expresamente sobre la pregunta que sirve como título -algo simple y carente de interés-, sino que es la reformulación de dos pensamientos que parten de tradiciones intelectuales e incluso de disciplinas distintas -concretamente el funcionalismo lingüístico en el caso del primero y la tradición fenomenológico-hermenéutica filosófica en el del segundo- para que puedan entablar un diálogo, partiendo de supuestos diferentes, en torno a un tema sobre el que pueden pronunciarse si y solo si extraemos ciertas inferencias de las tesis desde las que parten sus respectivos trabajos. Es por esto por lo que resulta di- 
fícil expresar estos pensamientos en una terminología mutuamente inteligible. Eso sin contar con que, por supuesto, hay todo un suplemento de referencias a otras obras como añadido a estas dos referencias principales.

El esquema de trabajo de este artículo es el siguiente: 1) análisis de los términos implicados en la pregunta que da título al artículo; 2) contextualización de la semántica del hablar en el pensamiento de Coseriu; 3) pertinencia y crítica de la crítica de Ricœur a los límites del estructuralismo para establecer una semántica del hablar, junto a un análisis de sus sugerencias; 4) examen de los esfuerzos realizados por el estructuralismo para superar la depuración epistemológica que realizan sus condiciones de partida; 5) delimitación del alcance de la crítica de Coseriu a la semántica cognitiva a partir de ciertas objeciones planteadas al límite trazado entre semántica estructural de la lengua y semántica del hablar; 6) sugerencias metodológicas sobre qué paradigmas teóricos pueden dar cuenta del objeto de estudio de la semántica del hablar.

La tesis que se intenta argumentar en este artículo es que no puede establecerse un estudio consistente de la semántica del hablar desde los presupuestos teóricos del estructuralismo, pero esto no implica que no deba reconocerse un espacio propio para esta semántica del hablar ni que la semántica estructural, en el ámbito de la lengua, no cuente con una legitimidad epistemológica propia. A partir de ahí se propone que, de acuerdo a la caracterización que Coseriu concede a la semántica del hablar, a la que se equipara aquí con la semántica no incluida en el nivel particular -o, lo que es lo mismo, la semántica que atiende a las dimensiones del sentido y la referencia-, esta puede encontrar acomodo, en función de la parcela en cuestión que se aborde, en las semánticas mixtas ${ }^{1}$ y en la semántica cognitiva. Esta caracterización coseriana se ve, además, enriquecida con nuevos ámbitos asignables a dicha semántica del hablar, como el proceso de estructuración identificado por Ricœur.

1. Por semántica mixta se entiende originariamente una teoría híbrida, "al mismo tiempo prototípica y analítica" (Coseriu 1990, 240). Con este término, en general, se expresa una ruptura con una semántica ortodoxa de rasgos, principalmente cuestionando o bien el carácter cerrado y discreto de los rasgos o bien el binarismo en el análisis componencial (ver Casas 1999, 104-05; más información en la nota 26). Estos elementos cuestionados se sustituyen por una concepción más abierta de la aplicación del estructuralismo al ámbito de la semántica léxica (ver \$5), pudiendo integrar, en un mayor ahondamiento de su carácter mixto, algunas tesis provenientes directamente de la semántica cognitiva (tales como la adopción de alguna versión de la teoría de prototipos o integrar parcialmente ciertas posiciones parciales de la semántica de marcos, etc.). 
El interés investigador que suscita la semántica del hablar, inserta dentro de la lingüística del hablar, es que conforma aún un dominio en buena medida inhóspito. Se origina a partir de la percepción de cierto agotamiento en las investigaciones concernientes al objeto de estudio tradicional de la lexicología clásica y el desplazamiento hacia zonas tradicionalmente consideradas periféricas, bien en relación con niveles de la lengua diferentes al de la palabra, bien en relación con ámbitos tradicionalmente excluidos en la delimitación metodológica de la semántica analítica, en general, y de la semántica estructural o semántica de rasgos continental, en particular. Me refiero con ello a aspectos insertos en lo denotativo o referencial, en lo comunicativo, etc., fenómenos excluidos en pos de la salvaguarda de una genuina semántica lingüística. ${ }^{2}$ Queda, en consecuencia, justificada la pertinencia de esta indagación.

\section{EXPLICACIÓN PROPEDÉUTICA DE LOS TÉRMINOS IMPLICADOS EN LA PREGUNTA: CONSISTENCIA, SEMÁNTICA DEL HABLAR Y ESTRUCTURALISMO}

Para facilitar la tarea de comprensión al lector, se va a realizar un análisis pormenorizado de los términos que están incluidos en la pregunta del título del artículo. La pregunta formulada parte de un término preciso de consistencia en lógica: aquello que está libre de contradicción. Por consiguiente, la pregunta del título se debe leer como si construir una semántica del hablar partiendo de presupuestos estructuralistas no encierra contradicción. A partir de aquí, los términos utililizados que requieren clarificar los conceptos a los cuales se remiten son semántica del hablar y estructuralismo.

\subsection{Semántica del bablar}

Sirva como primera aproximación sobre el siguiente término, y se dice "primera aproximación", puesto que en esta tarea estriba parte del desafío de

2. Menciono tangencialmente, en pos de una mayor precisión terminológica, que por semántica analítica entiendo aquella que analiza los significados como rasgos distintivos y definitorios, siendo la semántica estructural europea o semántica de rasgos continental aquella que, además de esto, distingue entre relaciones de significación y relaciones de designación y se centra en las relaciones de significación de las palabras con otras palabras en una lengua determinada. Utilizo esta terminología por ser más próxima al texto de Coseriu (1990), que discutiré más adelante, pero ya Casas Gómez $(2002,135-36)$ explica la conveniencia de reservar el término semántica analítica para una de las tendencias básicas de la semántica "tradicional", a saber, aquella dedicada al análisis en torno a los componentes del signo lingüístico. 
responder la pregunta, que semántica del hablar no es más que lo que su nombre indica: un estudio de los fenómenos del significado implicados en el habla. Inténtese, empero, corregir algo de la vaguedad e imprecisión propias de este primer acercamiento. Se colige, en primera instancia, que el babla se contrapone, siguiendo laxamente la oposición saussureana, a lengua, de forma que la semántica del hablar se entiende en tanto que se opone a la semántica de la lengua. Así se le aplica las propiedades propias del habla: especialmente su carácter asistemático y actualizado, en oposición a la lengua, sistemática y potencial. Esto marca un encuadre diferente para los fenómenos semánticos: en el caso de la semántica de la lengua, el marco es el del código lingüístico en tanto que sistema formalizado a partir de la idiosincrasia propia de las lenguas (i.e., de las relaciones sistemáticas internas que entabla con el resto de las unidades conformantes de la lengua natural específica), mientras que, en la semántica del hablar, los fenómenos semánticos se encuadran en la actualización propia de las posibilidades no consumadas del sistema de la lengua -no consumadas en el sentido de no empleadas, no en el sentido de no normalizadas, si se sigue la tricotomía coseriana de sistema/norma/habla-. Esto supone necesariamente, en el plano de la semántica del hablar, una realización en el discurso o en el texto o, si se desea enmarcar en un nivel inferior de la lengua, en el enunciado en tanto que actualización de la oración. Este marco no es inocuo, sino que tiene implicaciones sobre cómo se concreta el fenómeno semántico. Concretamente, la semántica del hablar se ve marcada, en primer lugar, por ser un contenido (semántico) específico en contexto proveniente de la actualización de los signos lingüísticos. Es, por tanto, una semántica implicada en el acto comunicativo. No obstante, es necesario notificar, antes de que se aborde específicamente los estratos del sentido y la referencia más directamente implicados en la semántica del hablar, que dicha semántica no se caracteriza por estos estratos en oposición a la codificación estructurada del significado, sino a partir de esta codificación estructurada en tanto que puesta en uso que presupone principios lógicos y enciclopédicos universales.

Dentro de los cuatro niveles del significar identificados por Casas Gómez (2002) -a saber, los niveles de la designación, el significado, la referencia y el sentido-, a partir de su trabajo de clarificación terminológica y conceptual de nociones similares empleadas en la historia de la semántica, la semántica implicada en el acto comunicativo sería, en primer lugar, una semántica del hablar en tanto que circunscrita por el nivel o el estrato del sentido, en el 
sentido de "correlato y actualización del significado en el discurso" (Casas Gómez 2005, 14). ${ }^{3}$

Sin embargo, no es la adjudicación primordial de este estrato o nivel del significar la única expresión identificadora de la semántica del hablar, puesto que esta también cuenta con una expresión en la direccionalidad que el signo lingüístico tiene hacia la realidad. Específicamente, se hace mención con ello a la referencia del signo lingüístico en tanto que actualizado. Es precisamente en tanto que el signo denota solo a través del acto del hablar que este puede seleccionar del mundo de lo real una referencia (denotatum), referencia que precisamente por la variabilidad propia del contexto es inconstante. ${ }^{4}$ Esto contrasta con las designaciones potenciales o de lengua que, en tanto parten del significado lingüístico, mantienen relaciones constantes y estructurables. ${ }^{5}$

3. Como se sabe, la noción de sentido adolece de una acusada ambigüedad en la historiografía, aunque pueden extraerse alguna propiedad común. El propio Coseriu identificaba al sentido como el plano en el cual el significado de lengua se hace a su vez significante para extraer el contenido del texto (o del discurso, podría añadirse), que es el sentido (1981, 284-85). No obstante, incluso en caracterizaciones previas provenientes de otras tradiciones, el sentido siempre ha contado con un rasgo de diferenciación respecto al contenido semántico codificado, por ejemplo centrándose en aspectos epistémicos del sujeto hablante: piénsese en la modelización de la noción en Frege como "modo de presentación" (157-58). Coseriu también añadía una dimensión subjetiva al apelar a la captación de la intención cuando sostiene que el sentido se identifica con lo que se "quiere decir" mediante las palabras $(1999,279)$. Estos factores epistémicos también están presentes en otros autores, así, por ejemplo, Báez San José, que ve el sentido como producto de la actividad del hablante de unir unidades almacenadas en su diccionario interiorizado con significados lingüísticos no incompatibles (24-25). De forma más amplia, en la historiografía cualquier factor que intervenga en la pura transmisión de contenidos en el acto particular de hablar se ha incluido de facto dentro de la noción de sentido-así, por ejemplo, Gutiérrez Ordóñez (1992, 57-63) incluye la decodificación del significado lingüístico, la significación referencial, la fuerza ilocutiva, las presuposiciones y los sobreentendidos-.

4. Aunque si nos atuviésemos estrictamente a Coseriu en sus inicios, algo que no se está llevando a cabo en este primer apartado, se ha de decir que, al menos en algunas de sus obras, solo habla de designación potencial y reserva designación real como correlato aproximado de referencia (1973, 295-96). Esta observación, grosso modo, no cuenta con implicaciones conceptuales ulteriores más allá del distinto significante empleado.

5. Expresado de forma más llana, el acto de hablar marca las variaciones que la singularidad de cada acto impone al hecho universal de que, en sincronía, las relaciones significativas y designativas sean siempre las mismas. Es decir, de forma todavía más simple, en el acto de hablar el sentido de una unidad léxica en el enunciado es singular, y mediante él o como consecuencia de él, la referencia, es decir, la entidad o entidades extralingüísticas seleccionadas por dicha unidad en nuestro enunciado es, o puede ser, diferente en cada acto. Ejemplificado, y limitándonos, como se puede apreciar, al nivel léxico, piénsese en la unidad léxica silla. Siguiendo el clásico estudio de Pottier, se define por una serie de semas con una base común que define el archisemema de su campo semántico -concretamente asiento- y otros semas que sirven para diferenciarlo de otras entradas léxicas incluidas en ese campo. Las relaciones que establece con los otros signos marcan las relaciones de significación, es decir, relaciones intralingüísticas que, al menos idealmente, no se pronuncian sobre la realidad extralingüística. Ahora bien, en el acto de hablar, es decir, en el discurso, la entrada silla denota potencialmente infinitas "sillas" 
Como colofón de esta caracterización, la semántica del hablar es el fundamento teórico de la pragmática y del análisis del discurso, cuya denominación es sobre todo empleada en la escuela funcionalista de lingüística, aunque se intentará defender en este artículo que, en último término, cuenta con más coincidencias con una semántica cognitiva basada en el uso o con ciertas semánticas mixtas que con la pragmática entendida al modo anglosajón -es decir, que es más una semántica del uso que una pragmática, propiamente-.

Con esta indicación y las previas en torno al sentido y a la referencia, se espera haber ofrecido pautas claras de identificación de la semántica del hablar. ${ }^{6}$

\subsection{Estructuralismo}

Resta aún por clarificar qué se entiende por "estructuralismo". Es esta una cuestión peliaguda en tanto que se conciba como necesaria la delimitación conceptual de esta corriente metodológica y epistemológica respecto al emparentado movimiento del funcionalismo. Incluso en un sentido laxo, se incluyen enfoques aún más alejados como el generativismo, como se verá en este mismo párrafo, por lo que resulta perentoria esta labor. En primer lugar, debe entenderse que el estructuralismo es una concepción metodológica y epistemológica que atañe a múltiples ciencias, y no solo a la lingüística. La identificación de las propiedades comunes a todos los "estructuralismos" lo encuentra Piaget (9) en: 1) la inteligibilidad intrínseca de las estructuras, basada en el postulado de que esta se basta a sí misma y no necesita recurrir a ninguna otra clase de elementos; 2) unas realizaciones, en la medida en que se han llegado a alcanzar efectivamente ciertas estructuras

distintas. En el discurso, además, el sentido de silla ha sido variado para ajustarse a esas potencialmente infinitas "sillas" distintas. Presentado más libremente, es un elemento incólume del sistema que deviene una potencialmente infinita variabilidad de denotata del mundo extralingüístico.

6. Debe aclararse, empero, aunque esta aclaración solo se comprenderá tras la lectura del siguiente parágrafo, que autores como el propio Coseriu reservan a veces la denominación de semántica del hablar solo para una semántica del hablar en general propia del nivel universal, mientras que la semántica del nivel individual sería una semántica ocupada del discurso o el texto (1999, 271). También debe tenerse en cuenta que, en otras fuentes, se acepta en un sentido laxo tipificar hablar, como realiza Vucheva (279-93) e incluso el propio Coseriu (1973), como la conjunción de los tres niveles (universal, histórico e individual). Cierto es que los niveles se reclaman entre sí y forman parte de una unidad pero, como se ha mencionado anteriormente, Coseriu reconoce en otros pasajes explícitamente como lingüística del hablar solo la referida al nivel universal (1999, 271-74; 1992, 90-91). 
y no otras. No obstante, en tanto que Piaget trata el estructuralismo puramente lingüístico (1980,87-111), se observa que incluye en él corrientes como el generativismo que se desearían excluir como estructuralistas en este artículo. La inclusión del generativismo sucede, a mi entender, porque en este caso Piaget está haciendo operativa la oposición que, tal como presenta Muñoz Núñez (1999b), defiende Dik (2) entre paradigma formal y paradigma funcional, haciendo buena la equiparación de Rojo (9) de paradigma formal a estudio del sistema lingüístico sin tener en cuenta los propósitos a los que sirven. Si se acoge la distinción de Nichols (97-117) entre teorías formales, estructurales y funcionales, la distinción entre formal y estructural serviría para diferenciar aquellas teorías que se ocupan de llevar a cabo un modelo formal y aquellas que no, como el estructuralismo. Esta característica constituye un primer indicio para excluir al generativismo de lo que se entiende por estructuralismo, entre otros.

Queda entonces la cuestión de qué criterios deben seguirse para la distinción entre teorías estructurales y teorías funcionales. En Nichols (97-117) estas últimas cuentan con un componente de atención a la situación comunicativa y a componentes pragmáticos, pero no es una atención per se, sino solo en tanto que dicha situación y dichos componentes afectan a la estructura. Dentro de esta línea, puede considerarse un acercamiento propedéutico a partir de Mounin (71-74), quien asemeja el análisis de la estructura lingüística al proceso metodológico de aislar las unidades que componen dicha "construcción" [sic]. En el proceso de aislamiento de las unidades, la pregunta de por qué criterio rige la existencia de estas unidades y no otras es lo que llevaría a la atención de la función, concretamente por su función de comunicación en el enunciado. En otras palabras, dos unidades se distinguen en tanto que cumplen una diferente función dentro del enunciado, lo que se consagra a través del principio de conmutación. ${ }^{7}$ No obstante, ha de decirse que dicho principio de conmutación es más bien una técnica metodológica del principio de funcionalidad,

7. Si bien esto parece suficiente para el establecimiento de clases, no parece bastarse tan claramente para la constitución de paradigmas, como lo son los campos léxicos, y aún menos para la ordenación de campos semánticos, que tienen, admítase o no, una clara dependencia respecto a la ordenación conceptual del mundo extralingüístico. Así, por ejemplo, cuando Germain (7795) se plantea los criterios de delimitación de las unidades conformantes del campo semántico, apela a criterios tales como la intuición, criterios extralingüísticos, definitorios, etimológicos, series derivativas, mediante el análisis distribucional de Apresyan, etc. En ningún caso parece librarse el criterio seleccionado de partir de un a priori conceptual, ni siquiera el último, que defiende Germain como el más cercano a ello. 
que, según Coseriu, debe complementarse con el principio de oposición, de sistematicidad y de neutralización (1999, 183-213).

Como señala Muñoz Núñez (1999b, 17-18), en la medida en que Coseriu o Martinet se autodenominaron estructuralistas funcionalistas, no serían funcionalistas si por ello se concibe desarrollar lo concerniente a la situación comunicativa y al aspecto pragmático -sentido, pues, en el que fueron funcionalistas Halliday o Dik-, pero sí, con sus matices, en el sentido en el que lo expresa Mounin.

Se ha perfilado qué es el estructuralismo contraponiéndolo a otras corrientes con las que guarda algunas propiedades en común. Toda vez que se han ofrecido rasgos generales del estructuralismo, se va a proceder ahora a especificar con mayor detalle los rasgos propios de la manifestación del enfoque estructuralista en la semántica léxica. Para ello puede tomarse como referencia los principios estructuralistas que han de cumplir idealmente los campos semánticos, que son las condiciones propias de toda estructura en lingüística, de acuerdo a la descripción de Gutiérrez Ordóñez (1992, 102-04). Concretamente se trata de: 1) el principio de totalidad: donde se declara una preeminencia del todo sobre las partes (donde la introducción o desaparición de una unidad puede afectar a todo el paradigma o solo a la microestructura en la que está inserta el paradigma, según la versión); 2) el principio de finitud: que proclama que el número de componentes de un campo ha de ser necesariamente limitado; 3) el principio de invariancia y discreción: lo que supone que las unidades deben considerarse como constantes y como cualitativamente diferenciadas entre sí; 4) el principio de diferenciación: que mantiene que toda unidad pertenece a un campo y solo a uno. Es importante retener en la memoria estos principios porque serán unos muy similares los que se presentarán posteriormente a partir de Ricœur como presupuestos del análisis estructural.

\subsection{Aplicación de la dilucidación conceptual de ambos términos a la pregunta}

Este recorrido introductorio ha servido para explicitar la pregunta que da título a este artículo, de forma que se ha desgranado, en la medida de lo posible, los conceptos a los que apuntaban los términos incluidos en ella. Así pues, podemos decir que la pregunta " $¿$ Es consistente una semántica del hablar desde los presupuestos teóricos del estructuralismo?” se traduce como “¿Está libre 
de contradicción una semántica enfocada en las dimensiones del sentido y la referencia, analizada desde algunos o todos de los presupuestos teóricos de totalidad, finitud, invariancia, discreción y diferenciación propios del estructuralismo?".

En el siguiente apartado, se examinará de qué forma y hasta qué punto Coseriu y Ricœur pueden ayudarnos en este menester, siempre teniéndose en cuenta, vuelvo a insistir, que literalmente ellos nunca respondieron a esta pregunta, pero establecieron ciertas bases que nos permiten establecer inferencias razonables desde sus posturas.

3. ESTADO DE LA CUESTIÓN: INCARDINACIÓN DE LA SEMÁNTICA DEL HABLAR EN EL PENSAMIENTO COSERIANO

La semántica del hablar, se decía, en tanto que preocupada por un fenómeno, el hablar, de carácter referencial y apegado al sentido, se circunscribe a un objeto de estudio eminentemente dinámico y comunicativo, en principio como opuesto a la lengua, marcada por la estaticidad y la sistematicidad. No obstante, se debe tener presente que esta es una caracterización genérica que no depende expresamente del marco teórico elaborado por Coseriu. Puesto que el objetivo marcado por la pregunta que sirve de título a este artículo es restringir las consideraciones al pensamiento de Coseriu y Ricœur, se deberá analizar, en primer lugar, no solo la idiosincrasia propia de la semántica del hablar en Coseriu, sino también los rasgos propios de una lingüística del hablar en la cual se integra como opuesta a una lingüística de la lengua tal como lo concibe el pensador rumano. Luego vendrá la aportación de Ricœur.

\subsection{Niveles del hablar}

El hablar en Coseriu está delimitado por tres niveles: el universal, el histórico y el individual. Esto significa que "el hablar es una actividad universal, que se realiza por individuos particulares, en cuanto miembros de comunidades históricas" $(1973,286)$. Estos niveles se deben entender como dimensiones que están siempre presentes en la acción de hablar y, por tanto, ningún nivel subsume lógicamente al otro. La génesis heurística de esta tricotomía proviene 
de la aplicación de la triada dialéctica hegeliana general-particular-individual (ver Vucheva 281 n. 2). ${ }^{8}$

A continuación, se va a describir brevemente cada uno de los tres niveles:

1) En el nivel más general del lenguaje, el universal, se dan aquellos fenómenos comunes a todo hablar, con independencia de la lengua en cuestión $(1987,20)$. Presumiblemente, este es el camino por el cual se agrega al decir el saber extralingüístico que no es subsumible bajo rasgos sémicos ordenados mediante relaciones opositivas y que configura, entiendo, los contornos del programa metodológico de una lingüística esqueológica o lingüística de las cosas. Esta lectura puede apoyarse textualmente si se considera que Coseriu reserva para este nivel universal los principios del pensar válidos en general y la cons-

8. Pueden apuntarse otras cuestiones de índole metodológica que no se insertan en el texto principal para no romper el hilo argumentativo. Por ejemplo, el relativo a la asignación a cada nivel de un tipo de estudio o disciplina, como muestra Loureda para los estadios de determinación progresiva del hablar en general en relación con la lingüística del texto en la obra de Coseriu (2013, 19-33): la hermenéutica como responsable del estudio del nivel individual, para así garantizar su idiosincrasia no generalizable; el estudio de la tradicionalidad para el nivel histórico; por último, la teoría general del discurso para el plano universal. Para ello, parte de un texto coseriano póstumo como es El problema de la corrección idiomática

9. En este artículo, siempre que se menciona el término nivel particular se le hace conceptualmente equivalente al nivel histórico. Nunca, bajo ningún concepto, se hace referencia con nivel particular al nivel individual. Esto se justifica por ser coherente terminológicamente con la triada dialéctica hegeliana das Allgemeine/das Besondere/das Einzelne (Inwood 302), de la que Coseriu toma las etiquetas universal/particular/individual (ver Vucheva 281 n. 2). Su significado, aplicado al ámbito de la metafísica, guarda bastante relación: lo particular contiene lo universal, pero lo representa por medio de su determinación (Hegel 284); esto se contrapone a lo individual, que es la completitud de la concreción de lo universal (Hegel 302). No obstante, es curioso que, en Competencia lingüística, a pesar de citar expresamente a Hegel, no se base en la evidente Ciencia de la lógica, sino en Enciclopedia de las ciencias filosóficas, lo cual le impide reconocer, en esta obra, el origen de la tripartición. Esta tripartición la encuentra, directamente referida al lenguaje y con una similitud ostensible, en la obra de Gabelentz, que distingue entre habla, lengua particular y capacidad lingiuistica (Coseriu 1992, 27) y el propio Coseriu lo reconoce directamente como fuente. Es en Competencia linguiistica donde Coseriu aborda nuevamente la tripartición en términos de plano lingüístico general/plano lingüístico particular/plano individual (1992, 92106), haciendo equivaler expresamente plano linguiistico particular con plano bistórico. Dado que, en la contraposición con la semántica cognitiva, interesa más subrayar que el nivel particular se realice en virtud de una lengua particular determinada a que dichas lenguas particulares se configuren a partir de una historicidad peculiar, parecen existir sobradas razones para justificar la elección terminológica de este artículo. Esto no obsta, empero, para admitir que el propio Coseriu cuenta con textos, como el de "Determinación y entorno", en los que contrapone "nivel histórico" con "nivel particular", teniendo claramente en mente una equivalencia entre "nivel particular" y el producto del nivel individual (a saber, el texto) (ver Coseriu 1973, 289). Ante esta posible ambigüedad terminológica, se reitera que aquí no se emplea este término con el último uso mencionado. 
tante referencia a hechos no lingüísticos tales como los contextos objetivos y el conocimiento general del mundo $(1999,271)$. El contenido correspondiente a este nivel universal del hablar es la designación de la realidad.

2) El nivel histórico, por su parte, remite al hecho de hablar una lengua determinada, con las particularidades léxicas y gramaticales que esto conlleva en cuanto a las formas de significado (ver Coseriu 1987, 128-47). En cuanto actividad es una lengua concreta (español, alemán, francés, etc.) y en cuanto saber es el saber hablar una lengua concreta (1999, 268-69).

3) Por último, el nivel individual integra la libertad del texto como producto final del hablar o del discurso como actividad creadora, como enérgeia. ${ }^{10}$ Es el nivel que se identifica cuando se advierte que un hablante concreto, en una situación comunicativa concreta, emite al menos un enunciado (o, en general, un acto lingüístico) (ver Coseriu 1999, 268). Por ello, la determinación de este nivel está configurada por cuatro factores: hablante, destinatario, objeto y situación (Coseriu 1992, 180-81). Como actividad se plasma en el discurso y, como producto, en el texto.

La lingüística tradicionalmente se ha centrado en el nivel histórico, lo que es lo mismo que decir que, como sostiene Coseriu, la lingüística ha sido hasta ahora sustancialmente una "lingüística de las lenguas" (1999, 271). Precisamente, dentro de los enfoques teóricos, solo la lingüística cognitiva parece haberse centrado más en el nivel universal, como se intenta mostrar en el siguiente parágrafo -disciplinas como la pragmática o el análisis del discurso, relativamente recientes, se ocuparían hoy en día, en parte, del nivel individual-.

Reconociendo Coseriu (1992, 90-91) que el hablar en general se corresponde con el nivel universal, reservando la lengua para el nivel histórico y el

10. Con el enfoque del nivel individual, Coseriu rompe con cualquier afán cientificista entendido en términos positivistas o neopositivistas en pos de preservar, entendemos, la ubicación constitutiva de la lengua dentro de un orden final, de la persecución de un télos, respetando así, como dice Martínez del Castillo (139), la actividad creadora que implica el hablar, aunque siempre inserta en la historicidad de la lengua. Esto tiene como consecuencia negar a la lengua una determinación distinta a la de su fin: concretamente, insertarla en un orden causal ajeno. Entiendo, en todo caso, que estas afirmaciones no son consustanciales con el planteamiento estructuralista, ni siquiera considero que se tenga que oponer el hallazgo de estructuras o el respeto a la libertad del hablante con la investigación de las causas. 
discurso o el texto para el nivel individual, se colegirá que es el nivel universal el más apropiado para contextualizar sus afirmaciones en su crítica a la semántica cognitiva, como se explica con mayor detalle en el siguiente epígrafe (ver $\$ 3.2)$. No obstante, debe mostrarse ahora las consecuencias que provoca centrarse solo en el nivel universal.

\subsection{Caracterización de la semántica del hablar a partir de su clasificación por niveles}

A partir de la atribución de ciertas propiedades intrínsecas a cada nivel, recién expuestas, Coseriu reconoce la asignación a cada uno de los niveles (universal, particular o histórico e individual) de los tres estratos del significar que él reconoce, de entre los cuatro que hemos mencionado antes, a saber: el estrato de la designación, el estrato del significado y el estrato del sentido -donde Coseriu agrupa la designación y la denotación del anterior parágrafo dentro de la extensión del término designación-. Así, la designación, en tanto que referencia a la realidad, no está vinculada a una lengua determinada, por lo que se ubica dentro del plano universal. Por su parte, el significado se corresponde siempre con el nivel particular en tanto que es dependiente de la forma en la que se estructura el contenido semántico en una lengua particular. Por último, el sentido, al ser lo que va más allá de la designación y el significado debido a que, entre otras cosas, transmite la intención del autor del discurso, pertenece al nivel individual (ver Coseriu 1992, 96).

Se origina una serie de consecuencias en relación con la caracterización con la que fue dotada la semántica del hablar en el apartado anterior. La atribución a la semántica del hablar, tal como fue definida fuera de los parámetros coserianos, tanto del plano del sentido como del de la referencia (similar, pero no idéntico, a designación en Coseriu), supone dividir entre semántica de la lengua (nivel particular) y todo lo demás como semántica del hablar. Debe entenderse, empero, que estos planos se reclaman en el uso. Como afirma Vucheva (284), las categorías de la designación (propia del nivel universal) y la del sentido (propia del nivel individual) se sitúan fuera de la lengua, pero contribuyen sustancialmente a la realización del hablar. Esto es debido a que, aunque actualmente se reconozca abiertamente que puede existir comunicación sin emisión de tipo lingüístico, la mayor parte de las producciones individuales (i.e., la mayor parte de los enunciados que componen un texto o un discurso) son lingüísticos. Ello implica que hacen uso de todos los niveles simultáneamente, aunque, en tanto que lingüística del hablar, el énfasis re- 
caiga sobre los niveles universales -lo común y presupuesto a todo hablar-y lo individual -lo irreductiblemente único de cada enunciado-, siendo, por lo demás, el nivel particular el más fácilmente asimilable desde una perspectiva metodológica a los requisitos de la constitución de la ciencia -y así lo afirma también Coseriu (1999, 270)-.

Dado que uno de los objetivos de este artículo es confrontar la crítica de Coseriu a la semántica cognitiva, el nivel universal se vuelve el más pertinente, en tanto que hay una referencia tanto a los contextos generales y la experiencia del mundo como a las cosas mismas -y es precisamente este ámbito el que parece adjudicarle Coseriu cuando trata esta semántica proveniente de otra tradición lingüística (ver 1990, 278-79)-. El nivel particular, que atañe al sentido, también se verá superficialmente comentado, pero no se abordará con profundidad en este estudio.

\subsection{Análisis de la epistemología y metodología propias de la semántica del hablar en Coseriu}

Dados estos condicionantes, resta aún por mencionar qué depara al nivel universal del hablar, entendido, como expone el propio Coseriu en la obra Competencia lingüística (ver 1992, 90-106), en la forma de actividad, saber y producto. Recuérdese lo aseverado: el contenido expresado por el decir se distingue a través de tres planos: la designación o referencia, el significado y el sentido. Puesto que es la designación la situada en el plano lingüístico general, en su dirección hacia los objetos extralingüísticos, supone el plano propio de este nivel universal.

En este punto ya se anticipa la reserva de la noción de significado para el significado lingüístico dependiente de cada lengua particular, supuesto que será relevante posteriormente. Ahora bien, se comienzan a vislumbrar dos problemas.

En primer lugar, obsérvese que, en principio, sería el significado lingüístico (en tanto que significación de lengua) el único objeto de estudio sistematizable en términos estructuralistas. Debido a ello, hay un afán reiterado en Coseriu y otros funcionalistas ${ }^{11}$ de separar, como se expone en Principios de semántica estructural (1981, 95-107), a las palabras de lo no estructurable,

11. Se utilizará aquí ambos términos, a saber, estructuralismo y funcionalismo, indistintamente, con las matizaciones del anterior parágrafo - por tanto, no refiriéndonos al funcionalismo anglosajón en ningún caso-. 
como las terminologías; del conocimiento de las cosas, como distinto del conocimiento de las palabras; de las asociaciones de la realidad diferentes a las asociaciones puramente lingüísticas de las palabras; por último, se asevera la distinción ineludible entre la estructura lingüística y la estructura de la realidad u ontológica. Esta depuración de todo lo que no es estrictamente lingüístico es, en el fondo, la depuración de lo que no es estrictamente estructurable, pues la razón metodológica principal de ese ejercicio es que solo mediante esa delimitación es posible recoger el contenido lingüístico bajo las condiciones propias de toda estructura que se expusieron a partir de la mención previa a Gutiérrez Ordóñez (1981, 34-45): totalidad (como preeminencia del todo sobre las partes), finitud (el número de componentes ha de ser limitado), invariancia, discreción y diferenciación (cada palabra pertenece a un campo, en el caso de que hablemos de campos o paradigmas léxicos). La imposición de estas condiciones, en caso de que sean consideradas conditio sine qua non para la aplicación del estructuralismo, genera el problema de hasta qué punto serán aplicables en otros niveles diferentes del nivel particular.

En segundo lugar, es menester recordar que el saber elocutivo propio del nivel universal recogía, como se expuso, conocimientos que van mucho más allá de los ceñidos al significado lingüístico, los cuales se presuponen, a la vez que son condición de posibilidad del acto de designación. Se apunta con ello a la congruencia con los principios más generales de las cosas (ver Coseriu 1992, 107-13) y a las restricciones generadas a partir de nuestro conocimiento de las cosas (ver Coseriu 1992, 114-24). En estos aspectos también rige igualmente una separación entre lo designativo y lo significativo en relación con lo universal y lo particular, respectivamente (ver Coseriu 1992, 132-35), lo cual genera un problema porque persiste la pregunta al respecto de cómo se articularía el paso de la significación a la designación, más allá de intentos clasificatorios que no alcanzan lo explicativo. ${ }^{12}$

12. Un conato de relación entre ambos lo podemos encontrar en obras como El hombre y su lenguaje (ver Coseriu 1991, 53-54, n. 4), donde Coseriu, utilizando una terminología marcadamente premoderna que habla de entes en vez de objetos, asigna al significado la organización de la experiencia humana en modos de ser; contendría así el ser de las cosas, pero no la aplicación a los entes. En la relación con la designación, cabría decir que el significado es la posibilidad de la designación y la designación, a su vez, es lo posibilitado mediante el significado. Sin embargo, en esto se avecina cierta tensión, pues si el significado es siempre dado por una lengua, esa posibilitación, en el acto concreto, no podría ser universal, sino solo en la condición de posibilidad del acto en su relación como signo lingüístico con los entes o cosas extralingüísticas (ver 1981, 130-33). La designación concreta, en tanto que mediada en su selección del ente, tendría que estar siempre lingüísticamente mediada, incluso aunque las cosas extralingüísticas, claro 
$\mathrm{Al}$ hilo de los dos problemas recién expuestos, debe realizarse una observación. Nótese que aún no ha sido posible ofrecer una delimitación metodológica propia del saber universal del hablar del mismo modo que se ofreció, por ejemplo, una tarea de índole hermenéutica para el saber particular (ver nota 8). Para comprobar hasta qué punto es así, deben explorarse otros textos coserianos a los hasta ahora propuestos. Por ejemplo, se encuentra algo parecido a esto en Teoría del lenguaje y lingüística general (ver 1973, 285-323), concretamente en el estudio denominado "Determinación y entorno". Allí, Coseriu reconoce la necesidad de cierta lingüística del hablar. Es importante resaltar, puesto que adquirirá especial importancia después, que la lingüística del hablar se considera como otra lingüística solo porque se acepta implícitamente la clásica distinción de Saussure entre langue y parole. ${ }^{13}$ Se anticipan ideas desarrolladas en detalle en Competencia lingüística y ya recogidas aquí, a saber: el hablar como actividad y como producto y los distintos niveles (universal, histórico y particular) de este. Incluso se realizan afirmaciones claramente concesivas afirmando que toda la lingüística es siempre lingüística del hablar y que no hay otra lingüística $(1973,287)$, que la lengua se debe explicar desde el hablar y se concede el espacio metodológico de estudio para la constitución de una lingüística del hablar en sentido estricto. No obstante, no puede evitar reconocer explícitamente la carencia de una lingüística del hablar en el nivel universal $(1973,289)$. Desafortunadamente, poco más se anticipa en esta obra sobre tal empresa.

En la postrera Competencia linguiística $(1992,148)$, así como en "Semántica estructural y semántica cognitiva" (1990), Coseriu sigue insistiendo en la necesidad de esa lingüística apegada a lo designativo, a la cosa, esa linguíistica esqueológica que aclare cuál es la aportación del conocimiento general de las cosas al hablar. Albrecht (41-54), más recientemente, sigue igualmente insis-

está, serán, al menos ontológicamente, las mismas para todos independientemente de la lengua que se emplee para designar. En este mismo texto, la designación acogería a su vez fenómenos pragmáticos como la ironía en la llamada designación metafórica (designación a través de un ser otro que el del ente designado) y la designación múltiple (designación del mismo ente a través de varios modos de ser). La adopción de la delimitación metodológica entre designar y denotar ayudaría igualmente para aclarar la potencialidad o actualidad de la designación.

13. Recuérdese que Coseriu considera "insuficiente" esta distinción entre langue y parole (1992, 76) y hace equivalerla, dentro de la tripartición que se mostró entre nivel universal, particular e individual, al habla con toda la actividad del hablar (nivel individual completo) y a la lengua con el saber hablar comunitario (i.e., el saber idiomático, un aspecto del nivel particular). No obstante, esto no invalida que el punto principal de la aseveración: toda lingüística del hablar lo es en tanto que se opone a una dimensión del lenguaje que no es hablar, sea la langue saussureana en sentido estricto o delimitándose solamente a partir de lo que no es el hablar. 
tiendo en la necesidad de esa lingüística que estudie la contribución del conocimiento de las cosas a la configuración y el funcionamiento del lenguaje, pero igualmente lo deja in albis, señalándolo como tarea para la tercera generación de discípulos coserianos.

En resumen, por más que se rastree, no se encuentra una delimitación metodológica propia del saber universal del hablar. No considero que esto sea una casualidad, cuya consecuencia palpable sea que esta lingüística del hablar en el nivel universal haya sido postergada durante estas décadas sin apenas avances significativos. Una primera labor para solventar esta dificultad sería elaborar una fijación de índole metodológica sobre si emprende un camino puramente estructuralista, tal como se lleva a cabo para el nivel particular, para lo cual hay que fijar en primer lugar si esto es posible, o si, por el contrario, se dedica, como parece condenarla Coseriu, a seguir pasos menos exactos y científicos mediante apelaciones vagas al discurso o a la designación-apegados a lo que él llama la gramática del hablar ${ }^{14}$ (1973, 289-90), a estudios teóricos de la determinación y el entorno en general (1973, 291-323), a una lingüística de las cosas o esqueológica o a una lingüística enfocada en la competencia cognitiva o en una teoría general de los juicios, como propone Vucheva (279-93)-. ${ }^{15}$ Establecer las condiciones de posibilidad de una lingüística y, más concretamente, de una semántica del hablar del nivel universal, será la tarea del siguiente epígrafe y, para ello, Ricœur nos servirá de ayuda.

\section{IMPOSIBILIDAD DE UNA LINGÜÍSTICA DEL HABLAR DESDE LOS PRESU- PUESTOS ESTRUCTURALISTAS. LA POSICIÓN DE RICCEUR}

\subsection{Planteamiento}

En primer lugar, voy a intentar mostrar que el propio Coseriu, indirectamente, niega la posibilidad de que esta lingüística esqueológica, al menos centrada en su aspecto puramente designativo, sea posible en el marco del estructuralismo -o, lo que es lo mismo, niega la parte más ambiciosa de una

14. En concreto, la gramática del hablar es la técnica general de la actividad lingüística, compuesta por las funciones y los instrumentos del hablar.

15. Esta perspectiva sería aún más desoladora si se recuerda que se ha defendido que la lingüística del hablar en tanto que hablar también incluye el nivel individual, pues dicho nivel tendría que ser estudiado a partir de una estilística del hablar o, enfocando el asunto desde los enfoques filosóficos y no tanto desde las disciplinas asignadas concretas, a partir de un enfoque hermenéutico. 
semántica del hablar del nivel universal-. Recalcaré, precisamente, para lo que me serviré de Ricœur, que además no es posible precisamente porque el estructuralismo, que posibilita la estructuración mediante relaciones opositivas de rasgos sémicos, lo consigue mediante la depuración de todo aquello que remita a entidades extralingüísticas. En definitiva, mi tesis, la cual adelanto, es que una lingüística esqueológica seria, consistente y que evite generalidades filosóficas pasaría por quebrar al menos una o todas de las cinco condiciones antes mentadas: totalidad, finitud, invariancia, discreción y diferenciación.

Ricœur se menciona en este punto porque se dedicó, en varias de sus obras -entre las que se puede citar el tomo segundo de Le Conflit des Interprétations, los ensayos que integran Interpretation Theory. Discourse and the Surplus of Meaning o, incluso, en otras de forma algo más indirecta como en La Métaphore Vive, entre otros textos reseñables- a abordar la relación entre hermenéutica y estructuralismo, concretamente a identificar una serie de presupuestos en el estructuralismo lingüístico que, grosso modo, recuerdan a las condiciones o principios que debe seguir cualquier estructura merecedora de tal nombre en algún nivel de la lengua -i.e., a las condiciones nombradas en el párrafo anterior-.

Rastrea el origen de estos presupuestos en la obra de Saussure, a la que adjudica un alcance parcial, y más extensamente a Hjelmslev. En líneas generales, Ricœur (1975) considera que el tipo de inteligibilidad del estructuralismo triunfa en aquellos casos en los que: se puede trabajar con un corpus constituido y muerto, establecer un inventario de elementos y unidades, colocarlos en relaciones opositivas, preferentemente binarias, y establecer un álgebra o combinatoria de esos elementos y de esas parejas en oposición. Este proceder parte de una serie de concesiones epistemológicas (ver Ricœur 2006, 19-20), que expongo y relaciono con los principios anteriormente mencionados para la constitución de estructuras:

1) la prioridad de la sincronía sobre la diacronía, por presuponer mayor inteligibilidad en la constitución del sistema que en el cambio, lo cual casa con la prerrogativa establecida por el anteriormente introducido principio de totalidad;

2) la presunción de finitud, algo relativamente claro para el sistema fonológico, pero que también parece aplicable al nivel léxico, al que tradicionalmente ha estado vinculado la semántica estructural; véase el claro correlato que guarda con el principio de finitud; 
3) ninguna entidad del sistema tiene más significado que el que proviene de su oposición a otras unidades de su mismo nivel -los principios de invariancia, discreción y diferenciación traídos a colación con anterioridad constituyen prerrequisitos metodológicos para cumplir este postulado metodológico-;

4) en los sistemas finitos las relaciones siempre han de ser, y lo son en caso de constitución exitosa de dicho sistema, inmanentes a estos, lo cual es consecuencia previsible de la aceptación del principio de finitud. Esta última condición, a pesar de su inocente apariencia, opera de fondo en la constitución de la dificultad para establecer las bases teóricas al respecto de cómo puede el signo lingüístico abrirse en el apuntar a las entidades extralingüísticas en el mundo de lo noemático y lo ontológico -esto es, en su abrirse hacia los conceptos y las cosas-.

Con la asociación trazada entre las concesiones epistemológicas que debe hacer el estructuralismo según Ricœur y los principios para la formación de estructuras esbozados por Gutiérrez Ordóñez, parece poder aseverarse una clara sintonía entre ambos, salvando la distinta terminología y el hecho de que este último acote su indagación a la constitución de una semántica funcional. Con esto se pretende asentar la idea de que la reflexión de Ricœur es extrapolable a la discusión que está siendo tratada, incluso aunque deba admitirse que la cuestión se aborda desde una visión panorámica y no desde una cuestión de detalle.

Así pues, si el enfoque estructuralista en semántica ha logrado resultados respetables, aunque no concluyentes, definitivos o completos, en lo que Coseriu llamaba el nivel particular (es decir, el de las lenguas), parece que lo consigue a partir de una depuración metodológica. Adelántese que esta depuración consiste en eliminar lo no asumible por el enfoque estructuralista como no pertinente como objeto de estudio -es decir, lo no sistematizable, lo no reflejable desde la perspectiva sincrónica, lo no clausurable en pos de volverlo finito (en relación al número de unidades, por ejemplo), lo no estructurable en términos de relaciones de oposición, lo transcendente al sistema, etc.-. Esto permite un análisis científico, pero perder de vista esta subordinación supondría tomar por un absoluto lo que no es más que un fenómeno: el lenguaje para el hablante folk no sería un objeto, sino una condición de posibilidad de la mediación.

Puede concebirse esta depuración del objeto de estudio como aceptable en tanto que forma parte de las condiciones de constitución de una 
ciencia como tal, pero la cuestión es ver qué consecuencias provoca dicha depuración. Precisamente Ricœur (1975, 94-99) denuncia que ello supone la exclusión de la inteligencia estructural de los actos, operaciones y procesos constitutivos del discurso al establecer una antinomia insuperable entre la estructura y el acontecimiento, el sistema y el acto. Probablemente esta aseveración amerite una explicación. Cuando Ricœur habla de la exclusión de la inteligencia de los actos, operaciones y procesos constitutivos del discurso, parte del truismo por el que el acto de hablar se convierte en algo externo, una realización individual que propicia la libre combinación de enunciados inéditos. En esta conceptualización de dicho acto de hablar, este se convierte en algo accesorio o accidental a la lengua en tanto que estructura, cuando precisamente defiende que es lo esencial a este. Al mismo tiempo, excluye el proceso, no solo entendido como cambio de un estadio a otro del sistema, sino en tanto que el proceso se vincula también a aspectos extralingüísticos: especialmente a la dimensión de la cultura y de la constitución humana como tal $(1975,94)$-lo que podría definirse como constitución antropológica-. En resumen, Ricœur (1975, 90 y 105) defiende que el pasaje a la unidad del discurso se resiste a la extrapolación del método aplicado exitosamente a la fonología.

Esta explicación puede parecer aún insuficiente si se juzga con estándares científicos -es decir, si el lector no se conforma simplemente con aproximaciones filosóficas-. Lo cierto, como se vio, es que Coseriu simplemente excluyó estas facetas situándolas fuera del nivel particular. Además, tampoco parece que en su trabajo se fuese más allá del rigor filosófico, pues, por ejemplo, la antinomia entre sincronía y diacronía no parece superarse, como sostiene Coseriu, quedándose sin más en concebir el lenguaje como enérgeia, como mantiene respecto a una de las manifestaciones de esa contraposición en Sincronía, diacronía e historia (ver 1978, 270-71) y lo mismo podría decirse de su tricotomía de niveles del lenguaje (general, particular e individual). No obstante, la captación de este problema puede explicar el salto metodológico que en Coseriu se opera desde un rígido estructuralismo en sus Principios de semántica estructural a su discurso más generalista e interpretativo de obras postreras tales como Competencia linguística o Lingiuística del texto. Esto sucede porque, a pesar de contar con distinto énfasis en cada uno de sus pensamientos, ambos autores coinciden en varios puntos: el primero, ambos reconocen que una ontología del logos o del decir tiene, antes que nada, lugar en 
el discurso; ${ }^{16}$ el segundo, los dos perciben que el nivel de manifestación del discurso cuenta con leyes originales en relación con los niveles anteriores. Es importante identificar estas coincidencias porque servirán como punto de partida para analizar las soluciones que proponen ambos autores.

\subsection{Propuesta de superación}

Como se procuró mostrar en el apartado anterior, las tensiones antes aducidas son el resultado de la objetualización de la lengua y su reducción a la definición que le asigna el método estructural. Se está, pues, en posición de comprender el rol que en la teorización del pensador francés jugará la comunicación -de la cual la lengua es considerada por el funcionalismo en general su instrumento, al menos sobre el papel-y, más concretamente, el habla. Como dice literalmente Ricœur $(1975,95)$ : "Hablar se convierte así en el acto por el cual el locutor, el hablante, supera la clausura del universo de los signos, en la intención de decir algo acerca de alguien: el lenguaje se supera como signo hacia su referencia y hacia su interlocutor". En este punto se plantea cómo se podría bosquejar la superación de esta antinomia, con las reservas que se expondrán en los siguientes apartados. ${ }^{17}$

En Ricœur directamente se abandona, de entrada, la idea de que el estructuralismo pueda explicar la idiosincrasia propia de la semántica del hablar. Sin embargo, si uno se fija en qué aporta la dimensión discursiva de la semántica del hablar al problema desde el enfoque estructuralista, este cumple el

16. Sorprendentemente, el propio Coseriu se alinea con esta postura cuando, rechazando el famoso apotegma saussureano según el cual hay que colocarse en el terreno de la lengua y tomarla como norma de todas las otras manifestaciones del lenguaje, lo invierte y asegura que es el terreno del hablar el que debe ocupar ese lugar-aunque stricto sensu este es solo un juicio epistemológico, no ontológico-.

17. He de aclarar previamente una delimitación más aguda de la problemática, no ya ciñéndonos solamente a Coseriu, sino en general a la semántica del hablar, pues supondría, al menos inicialmente, deslindar el asunto en, como mínimo, dos aspectos, de aquellos que tradicionalmente se asignan a la semántica del hablar. Un aspecto sería su dimensión denotativa (referencial) y otra su dimensión discursiva, que se ve traída a colación cuando se apela a la intención del hablante (es decir, a la esfera del sentido). Aclaro esto porque el aspecto de las cosas, esqueológico, afecta claramente a la semántica del hablar en su nivel universal (es decir, en relación a lo conceptual, a lo denotativo, a los presupuestos contextuales, etc.), pero sin agotar en ello toda la renovación que supone atender al discurso, es decir, al nivel individual, como articulador de una ruptura con la clausura de los signos. Una forma de articular ambas dimensiones es concebirlo de la siguiente forma: en el contenido de lo expresado en el decir, el sentido es la finalidad del discurso por el significado y la designación, pero en la constitución del sentido contribuye también el conocimiento de las cosas (ver Kabatek 42). 
rol de estructuración a partir de ir, en el proceso diacrónico, incorporando al sistema los aspectos extrasistemáticos (lo referencial y lo relacionado con el sentido), algo que se logra por dejar de ser, en el discurso, el sistema una mera entelequia, al emplearse en el habla.

Introduciré una explicación más pausada, lo que va a suponer iniciar una resumida propedéutica de su pensamiento que, en el siguiente epígrafe (ver $\$ 4.3$ ), recibirá un comentario crítico. En el enunciado, en la puesta en contexto de la oración, se transige ante la antinomia entre estructura y acontecimiento, es decir: hablar es, por recordar palabras de Ricœur $(1975,97)$, un acontecimiento actual, evanescente, mientras que el sistema es atemporal por ser virtual. El discurso en su actualidad consiste en una serie de elecciones sobre el sistema: ciertas significaciones son elegidas y otras excluidas. A su vez, estas elecciones provocan en el plano sintagmático nuevas combinaciones: se emiten enunciados inéditos, que componen la esencia del acto de hablar. Esta producción virtualmente infinita contrasta con el repertorio finito y cerrado de los signos en el sistema. En la instancia del discurso, además, el lenguaje tiene una referencia, como se acaba de decir. Finalmente, el acontecimiento del discurso implica también una forma propia de designar el sujeto del discurso, oponiéndose al anonimato del sistema. En la intersección de esos dos planos de la antítesis es donde se debe situar esa semántica del hablar. El filósofo francés $(1975,103)$ considera al signo como intermediario entre el sistema y el acto, puesto que, por una parte, dependería de la estructura, estableciéndose a partir de valores opositivos dentro de una virtualidad semántica: es en el momento del acto en el que la potencialidad deviene actualidad evanescente en el enunciado. Pero esta visión tiene una contrapartida: el enunciado, en cuanto acontecimiento, tiene una actualidad transitoria; no obstante, las palabras sobreviven al enunciado. Con esto lo que Ricœur quiere decir es que la palabra sobrevive a la instancia transitoria del discurso y queda disponible para nuevos usos. Retornando con un posible nuevo valor de uso, la palabra regresa al sistema y, en el retorno al sistema, le aporta una historia. $\mathrm{Y}$ se dice aquí el término palabra con toda la intención: pues es en la palabra, es decir, en el nivel léxico, donde Ricœur sitúa el punto de cristalización, el nudo de intercambio entre los acontecimientos y el sistema. En concreto (ver 1975, 104-05), el proceso se presenta como el concurso de un factor de expansión en virtud de la paulatina acumulación de contenido proveniente del uso de la palabra, que se topa con el freno de la limitación mutua de los signos en el interior del sistema. 
Si se adapta la posición de Ricœur a los propósitos del artículo, puede interpretarse que el proceso que describe constituiría a la semántica del hablar como una estructuración más que una estructura: la estructuración, en lo que tiene de proceso, hace quebrar parte de las condiciones estructurales, sin que esto suponga que no tenga sentido hablar de la estructura en sí misma como referencia última de la estructuración en el plano sincrónico.

\subsection{Análisis crítico de la propuesta de Ricour}

Surge ahora la cuestión al respecto de qué aportación real elabora Ricœur. Podría decirse que advierte de los límites del estructuralismo, concretamente de cómo opera la exclusión de diversos aspectos de su uso (tales como la aportación del habla, la repercusión del sentido, etc.), así como nos previene de la intrincada y no fácilmente aprehendible relación entre estructura y acontecimiento (habla). No obstante, este mensaje era más relevante hace unas décadas e incluso entonces ya existían fuentes alternativas que identificaban, estos problemas: piénsese en la postura de Bally por la que el signo actual precede siempre al virtual (98) o la del pensamiento de Benveniste por el que nada está en la lengua que no estuviera antes en la oración (131). Estas percepciones llegaron incluso a desembocar en ideas similares en el ámbito de la lingüística, que no contaron con suficiente seguimiento (ver Cazacu 113-29). Ciertamente, con esto no se quiere decir que hoy en día haya sido articulada satisfactoriamente la relación entre estructura y acontecimiento, o entre nivel particular y resto de niveles, siguiendo terminología coseriana: lo que se pretende constatar es que la ayuda de Ricœur es más un bosquejo tentativo que la formulación de una hipótesis comprobable o la defensa de una tesis lo suficientemente precisa como para ser contraargumentada. Es probable que Ricœur apunte a un fenómeno real, como es el de la estructuración en diacronía, pero no detalla la forma en la que esta procede basándose en la generalización a partir de casos particulares o en una proposición general que sea refutable o cualesquier otro método que pueda adscribirse al paradigma científico. Igualmente, tampoco explica cómo la estructura semántica de las lenguas particulares en su interrelación con el entramado noemático ayuda a la fijación de la referencia. En resumen, no hace lingüística, sino filosofía. Por ello, de la aportación del pensador francés se puede extraer principalmente su convincente argumentación al respecto de cómo y por qué el estructuralismo no puede explicar la forma de operar de los fenómenos implicados en la se- 
mántica del hablar y una sugerente heurística de estos problemas lingüísticos, que probablemente apunte, en especial con su visión del proceso de estructuración, a un fenómeno real. Ahora bien, dado que Ricœur no se inmiscuyó en profundidad en realizar teoría lingüística, ${ }^{18}$ tampoco tuvo en cuenta cómo podía replantearse ciertas condiciones de implementación del estructuralismo para dar lugar a una semántica más apegada al hablar. Precisamente este será el objeto del siguiente parágrafo.

\section{AMPLIACIONES DEL ESTRUCTURALISMO A PARTIR DEL CUESTIONAMIENTO DE AL MENOS UNA DE SUS CONDICIONES}

La pregunta que orbita alrededor de este artículo es, repítase, si es posible recoger desde una perspectiva estructuralista aspectos de la semántica del hablar que hasta ahora parecen más bien reservados a la especulación filosófica, en concreto, recoger esta semántica del hablar en su concepción más general posible como semántica designativa, semántica de las cosas, semántica de la producción discursiva, etc.

Antes de abordarse, se previno que Ricœur simplifica el planteamiento estructuralista al obviar los esfuerzos que desde el propio estructuralismo se hicieron para paliar las deficiencias explicativas que pueden seguirse de las viejas dicotomías saussureanas, ${ }^{19}$ aunque debe recordarse que Saussure nunca habló de estructuras, sino de sistemas. El problema es qué estatuto epistemológico se concedió a esos estudios. ${ }^{20}$ Martinet ya advirtió de los riesgos de

18. Lo cual no quiere decir que no fuese un conocedor de las corrientes lingüísticas de su época, estando al tanto de los avances significativos en esta disciplina hasta los años 80 del pasado siglo aproximadamente. Es más, junto con Habermas, puede sostenerse que Ricœur fue el filósofo más erudito del pasado siglo. No obstante, nuevamente hay que aseverar que, incluso cuando aborda sistemáticamente problemas relacionados con la lingüística, como por ejemplo en $L a$ metáfora viva (Ricœur 2001), lo hace con técnicas filosóficas, concretamente hermenéuticas: ofreciendo más marcos de interpretación que formas de proporcionar conocimiento científico.

19. Por "dicotomías saussureanas" se entiende aquellas dicotomías centrales que conforman el núcleo de la teorización en su Cours y que tuvieron una innegable influencia en la historia de la lingüística: concretamente me refiero a las dicotomías de sincronía/diacronía, lingüística interna/lingüística externa, fuerza de intercambio/espíritu de campanario y lengua/habla.

20. Y esto sin pronunciarnos aún sobre qué estatuto epistemológico debe tener esta investigación. Por un lado, adelanto que, si bien Saussure opone radicalmente sincronía y diacronía (155), Coseriu, al menos en teoría, advierte que la oposición pertenece a la lingüística, no al lenguaje $(1978,27)$. Esta negación permitiría a Coseriu deslindar a las lenguas particulares de la "fijeza" del sistema y ubicar el cambio lingüístico en su esencia: las lenguas se tornarían sistemas dinámicos, actividades creadoras, -concretamente, en tanto empleadas en el nivel individual-. Es más, mantiene que "la lengua no se da más que en el hablar de los individuos" $(1978,31)$. 
insistir en la estructura de la lengua sin referencia a su funcionamiento, propiciando desde esta nueva óptica una visión dinámica de los hechos lingüísticos $(1989,154)$. Así, encontrar la estructura en la lengua queda supeditado, según Martinet, a la delimitación del desempeño de su funcionamiento $(1971,16)$ y supone claramente la incursión del estructuralismo en el funcionalismo.

Igualmente, se postularon controvertidas unidades que rememoran el intento de extender el estructuralismo a lo no estructurable, al menos de entrada. Se recuerda con esto a los textemas, frasemas en niveles de la lengua superiores al léxico (ver Coseriu 1981, 116), o esos semas contextuales conocidos como clasemas en Greimas o virtuemas en Pottier. El carácter controvertido se refleja en la visión crítica que despertaron: del clasema sostiene Casas Gómez (2001, 283) que no puede ser caracterizado propiamente como sema contextual al no pertenecer a la lengua ni paradigmática ni sintagmáticamente; del virtuema mantiene Gutiérrez Ordóñez $(1992,90)$ que ha de ser eliminado de la descripción dado su carácter asistemático, individual e irrepetible; por último, Muñoz Núñez (1999b, 93) apunta la dificultad de distinguir variantes contextuales e invariantes de contenido.

Otras menciones en esta línea, dentro del funcionalismo, que pueden apuntarse al respecto de la ruptura con la rigidez que Ricœur atribuía al estructuralismo son: a) la admisión de unidades de la primera articulación pertenecientes a un paradigma o inventario abierto (ver Alarcos Llorach 1-16); b) el establecimiento de oposiciones que no tienen necesariamente carácter binario, sino ternario (ver Berruto 39-54; Casas Gómez 1999); c) la apertura a modelos dinámicos de representación del significado, que rompen con el requisito de una lista cerrada y discreta de marcas (ver Berruto 39-54); d) la obtención del valor del lexema a partir de procedimientos sintagmáticos dependientes de contexto (Berruto 39-54). No obstante, específicamente respecto a las propiedades $c$ y $d$, y quizá también para los puristas respecto a la $b$-la $a$, por su parte, puede verse como una limitación impuesta por la propia lengua a la aspiración del método estructural-, podría sostenerse que no son propias de un significado de lengua, sino de una integración de aspectos normativos, contextuales o incluso de uso -es decir, que estos puntos desafían la separación (artificiosa) entre lengua y habla, o entre nivel particular y los niveles universal e individual y, con ello, algunos de los postulados que se aceptaban para propiciar la cientificidad de la lengua o del nivel particular, tales como el principio de finitud o el principio de invariancia y discreción mencionados en el apartado anterior-. Esta vía es precisamente inspiradora al 
respecto de cómo afrontar una semántica del hablar y, parcialmente, concede cierta razón a Ricœur en tanto que supone recuperar aspectos pertenecientes, si no a la lengua, por lo que se acaba de exponer, sí al menos a la lengua inserta en la comunicación -las características de la lengua en el habla-, que fueron excluidos por cuestiones metodológicas.

\section{LA CONFRONTACIÓN ENTRE LA SEMÁNTICA COGNITIVA Y LA SEMÁNTICA ESTRUCTURAL COMO VÍA PARA PRECISAR LA APROXIMACIÓN METODOLÓ- GICA A LA SEMÁNTICA DEL HABLAR}

6.1 Caracterización de la semántica cognitiva. Semántica cognitiva como posible semántica de las cosas

Llegados a este punto, la cuestión que emerge es si un relajamiento en las condiciones metodológicas del estructuralismo sirve precisamente para adecuarse a las exigencias del objeto de estudio propio de la lingüística del hablar y, más concretamente, de la semántica del hablar. Para ello, será necesario centrarse en uno de los ámbitos identificados por la semántica del hablar, concretamente dentro del nivel universal del lenguaje delimitado por Coseriu, como es el de la llamada semántica de las cosas. Una teorización sobre esta semántica ayudaría, desde la lingüística, a la explicación, y no a la mera taxonomización, de la relación entre la designación (potencial) de lengua surgida a partir de la estructuración del significado de las unidades léxicas en dicha lengua y la selección de entidades o eventos del mundo en el acto de hablar (acto de denotar en el hablar). ${ }^{21}$

Para examinar esta vía, debe pensarse que semánticas ajenas a la tradición estructuralista parecen haber participado de este relajamiento de las condiciones estructuralistas. Concretamente, se hace referencia a la forma en la que la semántica cognitiva se constituyó (a través de la obra de Fillmore, Lakoff, etc.) contraponiéndose a otras semánticas, concretamente a las checklist theories of meaning, cuya condición es que el significado léxico se divida

21. Dejando a un lado, por el momento, el hecho de que esta denotación pueda ser metafórica, es decir, obviando el hecho de que, en el discurso, una entidad -o un objeto, si se quiere acentuar que es en tanto que en su relación con un sujeto hablante- puede ser referido a partir de una unidad léxica (un signo lingüístico en general) que no le corresponde de acuerdo a su significado literal. Según mi criterio, este tipo de denotación podría ser atendida dentro de la explicación a partir de mecanismos inferenciales que realiza la pragmática anglosajona (teorías neogricenas, de la relevancia, etc.). 
en componentes que deben ser satisfechos para ser usados apropiada o verdaderamente (ver Fillmore 123). ${ }^{22}$ Es una concepción del significado basado en el establecimiento de condiciones necesarias y suficientes para el empleo veritativo-condicional de una unidad del léxico con significado no gramatical que, empero, adolece de obviar las relaciones opositivas de significación entre las unidades de una misma lengua $-\mathrm{O}$, como sostiene Coseriu, que confunde las relaciones de significado y designación (1990, 245-46)-, algo de lo que sí se ocupa la semántica estructural europea. Esta semántica cognitiva se fija en el aspecto de la comprensión, entendiéndose como comprensión completa y compleja que el hablante intenta comunicar a cualquier texto y que el oyente busca construir (ver Croft y Cruse 26). Esto supone que es una semántica apegada al uso -de hecho, uno de sus postulados es que el conocimiento del lenguaje surge de su uso (ver Croft y Cruse 17)-, lo cual la hace al menos merecedora de ser considerada como una semántica que se pudiera ocupar del nivel individual del lenguaje, tal como lo expuso Coseriu. Pero, además, esta semántica exhibe una preocupación por insertar esa comprensión en modelos cognitivos idealizados (Lakoff), en dominios cognitivos (Langacker) o marcos (Fillmore), que, en la medida en la que suponen una conceptualización de la experiencia o del entorno que recubre la comprensión de los conceptos (ver Ibarretxe-Antuñano y Valenzuela 49; Croft y Cruse 50), casarían, aunque solo fuera parcialmente, con la caracterización de la competencia lingüística general propia del saber elocutivo del nivel universal de Coseriu como "conocimiento general de las cosas" $(1992,134)$.

Ciertamente, no parece que sea una idea descabellada esta comparativa, pues existen otros autores que la respaldan. Esta sugerencia de adjudicar a la semántica cognitiva el terreno de la semántica de las cosas es apoyada tanto por Albrecht (41-54), con bastantes reservas, como más abiertamente por Laca (9-10). Ambos asignan a la semántica cognitiva el papel de completar a la semántica estructural con los factores que determinan el uso e interpretación del lenguaje, la referencia, la clasificación de los actos lingüísticos, etc. Incluso Coseriu (1990) parece sopesar tal opción.

22. Esta teoría entraría dentro de lo que Lakoff (157-84) de forma más genérica llama el paradigma objetivista. 
6.2 Observaciones a la crítica de Coseriu a la semántica cognitiva. Redefinición de las fronteras entre la semántica de la lengua y la semántica del hablar

Dado que el ámbito de la semántica del hablar es amplio, atiéndase, en la medida en la que afecta a la semántica de las cosas, el asunto de la designación, como estrato del significar perteneciente al nivel universal (ver Coseriu 1999, 278-81; Vucheva 279-93). Para ello, centro ahora mi atención en un texto tardío de Coseriu (1990), en el que critica severamente la semántica de corte cognitivo. ${ }^{23}$

Compendiando los argumentos de Coseriu, buena parte de ellos se centran en criticar la confusión que los cognitivistas de nuevo cuño sufren entre sistema y norma y entre significado y denotación. En cuanto a la primera confusión, supondría para Coseriu confundir el significado prototípico con la variante normal más rica en rasgos y no identificar los significados periféricos como tratándose de la misma unidad semántica, pero dotada de menos rasgos (1990, 257); en lo que respecta a la segunda, estando de fondo la cuestión de la discrecionalidad en el significado en oposición a la continuidad de la realidad, Coseriu niega la gradualidad de los conceptos y adjudica esa heterogeneidad a las clases objetivas o cosas (1990, 261-62). En resumen, la primera crítica se centra en la incapacidad de aplicar propiamente el método estructural, en buena medida debido a que no reconocen el plano de estructuración del sistema, quedándose en la norma. Por su parte, la segunda crítica ahonda en que se hace depender la distinción entre lo lingüístico y lo extralingüístico (entre lo designativo de lengua y lo denotativo) a partir de la técnica metodológica de considerar a lo primero discreto y a lo segundo continuo. La primera crítica no es especialmente interesante en tanto que una de las condiciones de posibilidad de la semántica cognitiva es negar el plano de estructuración del sistema (y, en general, cualquier ordenación que no dependa directa o indirectamente de procesos cognitivos humanos). No responde a esa pregunta porque no la formula. La segunda, en cambio, sí manifiesta una problemática en la semántica estructural europea en tanto que la discrecionalidad es más un postulado teórico que una propiedad atribuible a la lengua y, además, ha sido cuestionado de facto en la historia de dicha semántica.

23. Para posibilitar el diálogo con el célebre lingüista rumano se obviará la cuestión de que él se centra en las primeras versiones de la teoría de prototipos, la más asentada y acabada en aquel tiempo, pero es necesario aclarar que, apenas un par de años después, Barsalou (1992) integra la teoría en marcos entendidos como una relación estructurada de dimensiones y valores, o que el propio Lakoff (1987), en un trabajo cronológicamente previo, insertó la estructura de las categorías dentro de modelos cognitivos idealizados. 
Antes de ahondar en la crítica, debe clarificarse que, por mera oposición, la forma en la que sea posible abarcar la semántica de la lengua afecta a la semántica de las cosas y del hablar en general, puesto que todo aquello que forme parte del nivel particular no forma parte por ello de los otros niveles y viceversa. He aquí, pues, la pertinencia de emprender tal tarea.

No obstante, si se desea llevar a cabo un examen riguroso de las condiciones de posibilidad de esta semántica de las cosas, primero se debe dilucidar dos puntos: 1) cuáles son los criterios metodológicos que trazan la frontera del significado del nivel particular (estructurable) respecto de los que no podrán estrictamente regirse por él; 2) qué aspectos pertenecen al objeto de estudio (las cosas), separándolos de aquellos que solo son la proyección de la aplicación de las condiciones propias del enfoque estructural. Este último esfuerzo supondrá la necesidad de distinguir entre qué depende de las cosas y qué de la mediación de los conceptos y, a su vez, distinguir entre qué depende de los conceptos entendidos desde el eje del que parte una perspectiva onomasiológica y qué depende de los significados como correlatos de significantes de una unidad léxica de una lengua particular.

Se está ahora en condiciones para afrontar qué aspectos conflictivos presenta el análisis de Coseriu. Ello conduce a señalar que, en este texto, Coseriu no parece advertir que:

1) la discrecionalidad no está en la lengua ni en los conceptos, sino en la metodología aplicada a la lengua y los significados. Como decía Martinet, el estructuralista "no es aquel que descubre estructuras, sino uno que las forja” (1971, 18); el mismo Hjelmslev representaba esto con en el apotegma "todo proceso tiene un sistema subyacente $-\mathrm{y}$ toda fluctuación una constancia subyacente-” (Hjelmslev 20) y acaba de introducirse la opinión de Ricœur al respecto. Es la metodología estructural la que exige e impone la discrecionalidad, que no debe y de hecho no es, desde la perspectiva del habla, aplicable;

2) los conceptos no son discretos, al menos no los conceptos entendidos desde un punto de vista psicológico. Sería ineludible rescatar la terminología de Heger (160): sería el sema, como correlato del semema en el plano de la forma del contenido, el que sería discreto, no así el noema. ${ }^{24}$ Mantengo que el concepto en tanto que representación

24. Entre los comentaristas hay cierta ambigüedad, pues, si bien Gutiérrez Ordóñez (1992, 36) 
mental de un objeto debe ser continuo o difuso en sus límites y además es en este ámbito de lo designativo donde la semántica cognitiva consigue describir con precisión cómo opera la mente humana en el proceso de categorización: hay sobradas pruebas de que esto es así. Incluso hay trabajos clásicos, como el de Hampton (91-116), en el que se pronuncia sobre un aspecto no excesivamente trabajado en la semántica cognitiva como son los límites en las categorías, aseverando que lo necesario para incluir a una entidad en una categoría de manera aceptable sería que la entidad $\mathrm{X}$ cayese dentro de la categoría $\mathrm{Y}$, sin que fuese necesario que todos los $\mathrm{X}$ se incluyesen en dicha categoría. Claramente, se percibe aquí que, para que se formule la anterior proposición de esa forma, debe existir una diferencia entre las categorías mentales y las categorías ontológicas, pues existiría una caracterización sobre la esencia de las entidades con independencia de la categoría mental asignada. Aún de forma más interesante, se apunta a cómo en el uso, en el acto denotativo, puede llegarse a afirmar la pertenencia a categorías sin que la confusión esté basada en una distinta asignación del referente en el acto de hablar, sino a una distinta asignación a la categoría. Esto supone además dar una explicación sobre cómo, en el acto de referir, pueden aplicarse nociones discretas a entidades continuas sin que esto cree ningún tipo de misterio insondable;

$3)$ en relación con el punto anterior, se presta a confusión, como hacen Coseriu (1990) y Laca (9-10), llamar a la semántica cognitiva "conocimiento de las cosas" o "lingüística de las cosas". En todo caso sería "lingüística de los conceptos", precisamente por lo expuesto en el punto 2. Además, las cosas son ignotas en sí mismas, a no ser que el término se emplee en sentido fenomenológico y posibilite una especie de captación directa del eidos mediante la epojé. Es útil rescatar en este punto la distinción entre designación potencial y designación real o

sostiene que entre semema y noema existe una correspondencia biunívoca y solo se distinguen en su naturaleza (lingüística y extralingüística, respectivamente), para Muñoz Núñez (1999a, 34) el sema, definido como unidad distintiva mínima del semema, está ligado a la estructura de una lengua dada, mientras que el noema no dependería de esta estructura. De esto se colige que no tendría que existir correspondencia biunívoca entre ambos. La propia Muñoz Núñez achaca esta ambigüedad al propio Heger cuando en el desarrollo posterior del texto encuentra ideas contradictorias, al sostener Heger que el noema es un concepto definido intensionalmente, por lo que no parecería conciliable con que no se adscribiera al plano de una lengua particular. 
denotación (Coseriu 1973, 295-96) o entre denotación y referencia (Lyons 106): precisamente cabe reclamar para ese saber universal del que se hablaba antes, cuando se mencionaban los principios más generales de las cosas (ver Coseriu 1992, 107-13) y las restricciones generadas a partir de nuestro conocimiento de las cosas (1992, 114-24), entre otros, que no puede provenir propiamente de las cosas sin más. Precisamente una de las enseñanzas de la semántica cognitiva a través de sus nociones y marcos es que, como se declaró, el conocimiento representado en un marco es una conceptualización de la experiencia que, con frecuencia, no se ajusta a la realidad ni al significado puramente lingüístico de una palabra. Por tanto, ese conocimiento de los principios generales y del conocimiento de las cosas al que se equiparó grosso modo es primeramente un conocimiento sobre nuestro entendimiento de las cosas, no sobre las cosas en sí mismas en cuanto clases objetivas.

El hecho de que este conocimiento de los principios generales y del conocimiento de las cosas es más un asunto de nuestro entendimiento que de las cosas en sí mismas en cuanto clases objetivas se percibe con claridad a partir del desarrollo que sufrió la semántica cognitiva. Piénsese en el ejemplo que Lakoff ofrece para el análisis de la entrada léxica martes (68-69). Puesto que el suceder de los días es en principio una cuestión natural universalmente constatable, no habría razones objetivas para que la conceptualización de los días de la semana fuera diferente entre lenguas. Pero el hecho de que haya sistemas de calendario alternativos, como el balinés, con reflejo en el léxico de la lengua, supone una objeción irrebatible a la hipótesis de que sean las cosas, y no nuestra conceptualización de las cosas (marcos en terminología cognitivista), el objeto propio de la semántica cognitiva;

4) aunque no se prodiga canónicamente en lo que respecta a la semántica, en el estructuralismo se admite la existencia de relaciones graduales entre miembros de una misma oposición en el sistema atendiendo a sus rasgos diferenciales. No obstante, estas oposiciones graduales contradirían buena parte del sustento epistemológico con el que Coseriu cuenta para la siempre difícil distinción entre lo lingüístico y lo extralingüístico. En todo caso, este es un motivo claro por el que autores como Trujillo negaban estas relaciones graduales y distinguían entre el diferente grado "real" de una misma propiedad y la diferencia 
lingüística discreta entre dos grados $(1976,185)$. Es precisamente la contraposición entre la continuidad de las propiedades de las cosas la que aporta una prueba decisiva para distinguir la propiedad del mundo real del denotatum "con respaldo" del rasgo "con respaldo", por recordar el ejemplo de Pottier (1963).

La continua persecución sobre si los significados acogen inadvertidamente rasgos de la realidad extrínsecos al sistema de la lengua proviene probablemente de que, a pesar de que en teoría son las oposiciones las que permiten deducir las marcas, lo cierto es que en muchos casos estas se obtienen a partir de una serie de pruebas que no parten del sistema, sino de la norma o del uso. Recuérdese el método de Pottier partiendo de la determinación de qué realidad corresponde con el signo a partir de encuestas, cuestión que se puede extender igualmente a la determinación de las oposiciones de los rasgos, que en muchas pruebas parten de la norma o del uso y se extienden artificialmente al sistema de la lengua. Con todo, hay que recordar que lo que menos debería importar es si los rasgos recuerdan a propiedades descriptivas de la realidad: en efecto, esto es precisamente un efecto lógico en el sistema a partir de que los signos lingüísticos apuntan a las entidades extralingüísticas o, lo que es lo mismo, a que existe de hecho una retroalimentación entre el sistema y el uso, como apuntaba Ricœur con su proceso de estructuración. Sin embargo, esto no afecta a que, en sincronía, el sistema de la lengua se constituya de forma endógama, es decir, cumpliendo la condición que Ricœur asignaba al estructuralismo, según la cual el conjunto de los signos considerado debe ser cerrado $(1975,92)$. Por ello, lo único que debe interesar aquí es si esas propiedades en el proceso de abstracción que supone su pertenencia al sistema, y que en puridad las constituyen como unidades sémicas totalmente ajenas a las propiedades del mundo, independientemente del hecho espurio de que cuenten con la misma etiqueta, se ajustan a los parámetros estructurales en la conformación de un paradigma léxico. En ocasiones, este punto entra en cuestión solo por la dificultad del establecimiento de criterios sistemáticos claros para la constitución de las relaciones entre semas y no tanto por el planteamiento en sí: son dificultades metodológicas, pero no una confusión conceptual de las diferencias entre ambos; ${ }^{25}$

25. Cabe además reseñar que tanto Langacker (9-20) como Lakoff (160) admiten que las construc- 
5) parece siempre minusvalorarse en la semántica estructural la proporción de léxico no estructurado existente (nomenclaturas o terminologías). Esta sería una razón simple y fácil para explicar la dificultad existente para cubrir extensas zonas del léxico por parte de las teorías del análisis sémico y de los campos léxicos (por la semántica estructural del nivel particular, en suma), pero una delimitación precisa de estas zonas contribuiría al estructuralismo tanto como un análisis opositivo de rasgos sémicos a la semántica estructural.

Con estas críticas, se está en posición de comprobar qué repercusiones tiene en la delimitación de la semántica de las cosas y del hablar en general.

\section{CONCLUSIONES}

La primera conclusión es que la gradualidad no es una propiedad completamente fiable en la delimitación entre qué pertenece a la semántica de la lengua (propia de la semántica estructural europea) y qué a la semántica del hablar. Esto se debe, en parte, a que el conocimiento del sistema léxico de una lengua proviene siempre del hablar, y esto produce de facto que se atribuya erróneamente propiedades de esta última a la primera. Esta posición, empero, parte del error metodológico de pretender que la semántica de la lengua cargue con la responsabilidad de explicar, al menos parcialmente, aspectos propios de la semántica del hablar. Así, por ejemplo, nada hay de anómalo en el hecho de que el sentido propio del nivel individual del hablar quebrante las férreas relaciones opositivas propias del sistema de la lengua.

Dicho error metodológico se refleja también, en su sentido contrario, en la pretensión de que las lenguas carezcan en tanto que sistema estructural de toda remisión al universo de las cosas, ni siquiera marginalmente. Pero precisamente por la capacidad de la lengua de referirse a las cosas (direccionalidad), esta conserva, a partir del proceso de estructuración que describió Ricœur, un reflejo de su origen: en la constitución de los semas, por ejemplo.

Igualmente, hay ciertos sectores del léxico que probablemente no ofrecen mayor estructuración que la propia de las entidades de la realidad -o de los conceptos que a ella se remiten, como se previno-. No obstante, esto no

ciones discretas son predominantes en las caracterizaciones de estructuras internas lingüísticamente codificadas, incluso aunque reserven un papel a la continuidad. 
es óbice para advertir que la parte puramente sistemática de la lengua, que es la perfilación de las unidades léxicas en tanto que pertenecientes a un sistema conformado a partir de relaciones opositivas, es aún hoy una tarea epistemológica abierta.

Por tanto, se puede considerar que los esfuerzos del estructuralismo por relajar las estrictas condiciones de esta corriente no conducen a una semántica de la lengua más precisa. En tanto que quebrantan ciertas condiciones claves dejan de ser semánticas de la lengua, al menos estructural enfocada al nivel particular, y en tanto que lo hacen para acoger propiedades de lo extralingüístico, como la continuidad, el carácter abierto del paradigma o la atención al contexto, llevan a cabo, sin advertirlo, los verdaderos comienzos de una semántica del hablar, con un terreno propio e independiente al de la pragmática o el análisis del discurso.

Se llega por lo anterior a aseverarse que una semántica del hablar, en lo que atañe a su dimensión designativa y denotativa, y que quisiese conservar cierto rigor científico sin conceder todo el peso explicativo a la creatividad del lenguaje, como lo hace Coseriu para el nivel individual, tendría que pasar por algún tipo de relajamiento de los rígidos principios que propician lo que Ricœur llamaba la clausura de los signos en el sistema. Ello se identifica parcialmente con lo que están llevando a cabo las semánticas mixtas. Estas se mencionaron brevemente antes cuando se habló del relajamiento por parte de algunos autores, como Berruto, de ciertos postulados del estructuralismo o con algunos presupuestos de la axiología iniciada con Martinet, aceptando la existencia de puntos limítrofes en la descripción lingüística (ver Muñoz Núñez 1999b, 49-65) -a partir de distinciones entre centro y periferia en el sistema (tal como propuso la Nueva Escuela de Praga) o parte discreta y parte variable; de la inclusión de la variación centrada en técnicas estadísticas de identificación de rasgos a partir de estudios estadísticos del uso en cuanto al enfoque metodológico (Berruto 39-54); de la consideración social del valor social y la frecuencia en el estudio del sistema (ver Mahmoudian 5-36), etc. por completar las medidas que ya se mostraron como esfuerzos del estructuralismo por superar sus limitaciones, tal como se vieron anteriormente-. Sin embargo, se da una diferencia crucial con las semánticas mixtas: estas vienen supuestamente a ocupar o, cuando menos, no parecen negarlo explícitamente, el lugar de la semántica lingüística lingüistica, por recordar la expresión de Kabatek, estructural. Dicha ocupación sería ilegítima en tanto que lo que realmente hacen es utilizar otros métodos para ocuparse probablemente de otro 
objeto de estudio: se centran en la lengua como norma, pero no en la lengua como sistema, incluso cuando a veces apunten a ella.

En cuanto a la determinación de qué papel jugaría la semántica cognitiva en el entramado teórico coseriano, debe tenerse presente que la semántica cognitiva no es, sin más, una semántica mixta. ${ }^{26}$ Sin ánimo de ir más allá de ofrecer una propuesta tentativa, la semántica cognitiva sí que recoge algunos de los puntos que Coseriu reserva para lo que llama el saber elocutivo (i.e., el saber propio del nivel universal), por lo que desempeñaría metodológicamente un rol complementario al de las semánticas mixtas. No solo ayudar a recuperar la información de trasfondo (background) que fija el significado literal tanto de unidades léxicas como de enunciados completos (ver Searle 175-96) a través de su noción de marcos cognitivos idealizados y similares, que es lo que Coseriu reclamaba grosso modo con su apelación al conocimiento general de las cosas (ver 1992, 114-25), sino que también estructura parte de lo que Coseriu llama principios del pensamiento (1992, 107-13), en tanto que, en muchos casos, más que principios lógicos son ordenaciones conceptuales de la experiencia que afectan a la producción e interpretación de enunciados. Huelga decir, empero, que esta semántica cognitiva debería sufrir un proceso de ajuste para volverla consistente con el papel que jugase un estructuralismo puro en el nivel particular de las lenguas. Dicho ajuste sería menor o inexistente en aquellas parcelas del léxico de una lengua que no se constituyesen a partir de relaciones opositivas, es decir, que lo hiciesen a partir de nomenclaturas ordenadas a través de criterios estrictamente conceptuales.

En cuanto a las intuiciones recogidas por Ricœur, más allá de su mera crítica a los límites del estructuralismo, puede sugerirse, en sintonía con este trazado programático de la semántica del hablar a la que se está procediendo, lo siguiente: que la asociación de la semántica del hablar con la estructuración constituye un verdadero episodio intermedio entre los aspectos sistemáticos de la semántica de la lengua y el mero hablar asistemático. Apunta al proceso por el cual lo referencial y el sentido van incardinándose progresivamente en la semántica de la lengua. No sería el acto de referir o el acto de enunciar

26. Recuérdese que Coseriu entiende por semántica mixta la combinación de planteamientos de la semántica cognitiva en el estadio en el que él la llegó a conocer (la teoría de prototipos) junto con la semántica estructural europea (Coseriu 1990, 240). En la práctica, en la semántica mixta se recoge cualquier tipo de semántica que, partiendo de los postulados de la semántica estructural europea, incumple, o no respeta completamente, al menos uno de ellos (sea la discrecionalidad, el añadido de marcas provenientes de la norma, la apertura o indeterminación en la constitución de paradigmas léxicos, la laxitud del binarismo, etc.). 
un acto inocente e inocuo que aplicase sin más en sincronía los aspectos puramente sistemáticos de la designación de lengua y el significado, sino que en cada denotación y en cada sentido, en cada acto concreto del decir, el acontecimiento (es decir, cada acto de hablar), recoge parte de lo extralingüístico, lo discursivo y lo cognitivo. La semántica esqueológica sería así algo más que aquello extrínseco que nos ayuda a comprender enunciados mediante la aportación de un saber sobre las cosas o sobre principios generales del conocimiento (es decir, la tarea parcialmente asignada a la semántica cognitiva), sino que sería de suyo además una semántica intermedia del hablar que ayuda también a integrar parcialmente esa energía creativa propia del hablar, esa enérgeia, en una teorización si bien no tan precisa como la que procura los estándares estructurales, sí al menos con ciertos patrones por hallar. Concretar esta propuesta supone, de fondo, arribar a un razonamiento parecido al que aplica Coseriu (1990, 258-61) cuando aborda la problemática de las categorizaciones de emergencia en su crítica a la semántica cognitiva: una cosa no categorizada puede introducirse en un molde que no le corresponde a falta de otro más adecuado y, en tanto que es de emergencia, el significado no cambia. Solo en la generalización y en la regularización el tipo de designación puede llevar a un cambio en todo el significado. Lo único que no acepta es que el cambio del significado pueda ser parcial, heterogéneo; pero si bien pudiera acordarse que este cambio no sería completo en el sistema, estos casos bien pudieran encontrar acomodo en esta semántica del hablar. Y hace bien en realizar esta distinción porque no se puede confundir el proceso de estructuración con la estructura: ambos campos tienen sus propias exigencias metodológicas. En resumen, pues, la estructuración, que formaba parte de una especulación filosófica, se comienza a ver como un fenómeno que se incluye como dentro del horizonte de lo explicable dentro del marco de la semántica del hablar en su vertiente diacrónica, al menos en teoría.

Es sin duda una tarea desafiante encontrar los principios heterogéneos de esta semántica del hablar, con una constitución propia, en tanto que esta semántica del hablar estaría al servicio de la semántica de la lengua. Probablemente este sea uno de los claros y difíciles retos de la investigación. Pero en lo que se refiere a la pregunta que abre este texto, espero haber aportado al menos indicios débiles sobre su respuesta, que resumo ahora: una semántica del hablar sí es inconsistente, es decir, genera contradicciones internas, con los principios del estructuralismo. No obstante, esto no supone negar que no pueda idearse una semántica del hablar al servicio de una semántica 
estructural de la lengua, respetándose, asimismo, a esa semántica de la lengua como contando con un objeto de estudio propio. A partir de ahí, el enfoque metodológico propio de las semánticas mixtas y de una semántica cognitiva adaptada al encaje con la semántica estructural del nivel particular se perfila como el más prometedor para acometer la tarea venidera de desarrollar sistemáticamente una semántica del hablar desde procedimientos científicos que recelen de aproximaciones especulativas.

Se concluye, pues, que el hecho de que la semántica de la lengua no sirva, en tanto que estructural, para constituir una semántica del hablar no significa que los métodos propios de la semántica del hablar deban suplantar a los de la semántica de la lengua. Por tanto, se responde con ello, tras este camino, a la pregunta que acoge el título: el estructuralismo, en tanto que aplique sus condiciones tanto ideales como realistas, no puede dar cuenta de una semántica del hablar, pero esto no implica que no urja una semántica del hablar con otro enfoque metodológico que preste servicio a la semántica de la lengua.

\section{OBRAS CITADAS}

Alarcos Llorach, Emilio. "Metodología estructural y funcional en lingüística". Revista española de lingüística 7.2 (1977): 1-16.

Albrecht, Jörn. "El paradigma incompleto de E. Coseriu: tarea pendiente para la tercera generación". Odisea 3 (2003): 41-54.

Báez San José, Valerio. "Las formas en -mente en una teoría fenomenológica integrada del acto de hablar, la expresión y el esquema oracional". En torno al adverbio español y los circunstantes. Ed. Gerd Wotjak. Tübingen: Narr, 1996. 1-40.

Baldinger, Kurt. Teoría semántica: hacia una semántica moderna. Madrid: Alcalá, 1970.

Bally, Charles. Le langage et la vie. $3^{\mathrm{a}}$ ed. Genève: Droz, 1965.

Barsalou, Lawrence. Cognitive Psychology: An Overview for Cognitive Scientists. Hillsdale, N. J.: Lawrence Erlbaum Associates, 1992.

Benveniste, Émile. Problèmes de linguistique générale. Vol. 1. Paris: Gallimard, 1966.

Berruto, Gaetano. "Una nota su semantica componenziale e analisi prototipica". Aspects of Language: Studies in Honour of Mario Alinei. Eds. Roberto Crespo, Bill Dotson Smith y Henk Schultink. Vol. 2. Amsterdam: Rodopi BV, 1987. 39-54. 
Casas Gómez, Miguel. Las relaciones léxicas. Tübingen: Niemeyer, 1999.

Casas Gómez, Miguel. "Origen y desarrollo del concepto de clasema". Actas del II congreso internacional de la Sociedad Española de Historiografía Lingüística. Eds. Marina Maquieira Rodríguez, María Dolores Martínez Gavilán y Milka Villayandre. Madrid: Arco Libros, 2001. 277-91.

Casas Gómez, Miguel. Los niveles del significar. Cádiz: Universidad de Cádiz, 2002.

Casas Gómez, Miguel. "Semántica de la lengua y semántica del hablar: fenómenos y disciplinas implicadas en su delimitación”. Entre semántica léxica, teoría del léxico y sintaxis. Eds. Juan Cuartero Otal y Gerd Wotjak. Frankfurt am Main: Peter Lang. 2005. 13-28.

Cazacu, Tatiana. "La structuration dynamique des significations". Mélanges linguistiques publiés à l'occasion du VIII-e Congres International des linguistes (Oslo, du 5 au 9 août 1957). Bucarest: Éditions de l'Academie de la République Populaire Roumaine, 1957. 113-29.

Coseriu, Eugenio. Teoría del lenguaje y lingüística general. $3^{\mathrm{a}}$ ed. Madrid: Gredos, 1973.

Coseriu, Eugenio. Sincronía, diacronía e historia: El problema del cambio lingüístico. $3^{\text {a }}$ ed. Madrid: Gredos, 1978.

Coseriu, Eugenio. Principios de semántica estructural. $2^{a}$ ed. Madrid: Gredos, 1981. Coseriu, Eugenio. Gramática, semántica, universales. Estudios de lingüística funcional. $2^{a}$ ed. Madrid: Gredos, 1987.

Coseriu, Eugenio. "Semántica estructural y semántica cognitiva". Homenaje al Profesor Francisco Marsá. Fornadas de filología. Barcelona: Universidad de Barcelona, 1990. 239-82.

Coseriu, Eugenio. El hombre y su lenguaje: estudios de teoría y metodología lingüística. $2^{a}$ ed. Madrid: Gredos, 1991.

Coseriu, Eugenio. Competencia lingiuística: elementos de la teoría del hablar. Madrid: Gredos, 1992.

Coseriu, Eugenio. Lecciones de linguïística general. $2^{\mathrm{a}}$ ed. Madrid: Gredos, 1999. Croft, William, y Alan Cruse. Linguiistica cognitiva. Madrid: Akal, 2008.

Dik, Simon Cornelis. The Theory of Functional Grammar. Vol. 1. Dordrecht: Foris, 1989.

Fillmore, Charles. "An alternative to checklist theories of meaning". Proceedings of the First Annual Meeting of the Berkeley Linguistics Society 1 (1975): 123-31.

Frege, Gottlob. Collected papers on Mathematics, Logic, and Philosophy. Oxford/ New York: Basil Blackwell, 1984. 
Germain, Claude. La semántica funcional. Madrid: Gredos, 1986.

Gutiérrez Ordóñez, Salvador. Linguiistica y semántica: aproximación funcional. Oviedo: Universidad de Oviedo, 1981.

Gutiérrez Ordóñez, Salvador. Introducción a la semántica funcional. Madrid: Síntesis, 1992.

Hampton, James. "The combination of prototype concepts". The Psychology of Word Meanings. Ed. Paula Schwanenflugel. Hillsdale, N. J.: Lawrence Erlbaum, 91-116.

Hegel, Georg Wilhelm Friedrich. Ciencia de la lógica. $5^{\text {a }}$ ed. Buenos Aires: Solar, 1982.

Heger, Klaus. Teoría semántica. Hacia una semántica moderna. Vol. 2. Madrid: Alcalá, 1974.

Hjelmslev, Louis. Prolegómenos a una teoría del lenguaje. 2ª ed. Madrid: Gredos. 1971.

Ibarretxe-Antuñano, Iraide, y Javier Valenzuela. Lingüística cognitiva. Barcelona: Antropos, 2012.

Inwood, Michael. A Hegel Dictionary. Oxford/Malden, MA.: Blackwell, 1992. Kabatek, Johannes. "Eugenio Coseriu, las tesis de Estrasburgo y el postulado de la lingüística lingüiśtica". Eugenio Coseriu in Memoriam. XIV Fornadas de lingüística. Ed. Rocío Vela. Cádiz: Universidad de Cádiz, 2013. 35-56.

Laca, Brenda. "La semántica de prototipos: ¿hacia una lingüística de las cosas?". Relaciones 1 (1984): 9-10.

Lakoff, George. Women, Fire, and Dangerous Things. Chicago: University of Chicago Press, 1987.

Langacker, Ronald. "The limits of continuity: discreteness in cognitive semantics". Continuity in Linguistics Semantics. Eds. Catherine Fuchs y Bernard Victorri. Amsterdam/Philadelphia: John Benjamins, 1994, 9-20.

Loureda, Óscar. "Notas sobre Eugenio Coseriu al hilo de su Lingüística del texto". Eugenio Coseriu in Memoriam. XIV Fornadas de lingiuística. Ed. Rocío Vela. Cádiz: Universidad de Cádiz, 2013. 19-34.

Lyons, John. Semántica Lingüística: una introducción. Barcelona: Paidós.1997. Mahmoudian, Mortéza. "Structure linguistique: problèmes de la constance et des variations". La Linguistique 16.1 (1980): 5-36.

Martinet, André. El lenguaje desde el punto de vista funcional. Madrid: Gredos, 1971. 
Martinet, André. "Linguistique générale, linguistique structurale, linguistique fonctionnelle". La Linguistique 25.2 (1989): 145-54.

Martínez del Castillo, Jesús Gerardo. "La teoría del hablar, una teoría del conocimiento". Odisea 3 (2003): 131-54.

Mounin, Georges. Claves para la lingüística. Barcelona: Anagrama.1976.

Muñoz Núñez, María Dolores. La polisemia léxica. Cádiz: Universidad de Cádiz. 1999a.

Muñoz Núñez, María Dolores. El análisis funcional del significado. Cádiz: Universidad de Cádiz. 1999b.

Nichols, Johanna. "Functional theories of grammar". Annual Review of Anthropology 13 (1984): 97-117.

Piaget, Jean. El estructuralismo. Vilassar de Mar: Oikos-Tau. 1980.

Popper, Karl Raimund. Búsqueda sin término: una autobiografía intelectual. Madrid: Alianza, 2002.

Pottier, Bernard. Recherches sur l'analyse sémantique en linguistique et en traduction mécanique. Nancy: Université de Nancy, 1963.

Ricœur, Paul. Hermenéutica y estructuralismo. Valencia: Pretextos, 1975.

Ricœur, Paul. La Metáfora Viva. Madrid: Trotta, 2001.

Ricœur, Paul. Teoría de la interpretación: discurso y excedente de sentido. México: Siglo XXI, 2006.

Rojo, Guillermo. "Estado actual y perspectivas de los estudios gramaticales de orientación funcionalista aplicados al español". Verba 21 (1994): 7-23.

Saussure, Ferdinand. Cours de Linguistique Générale. Lausanne/Paris: Payot, 1916.

Searle, John. The Rediscovery of the Mind. Cambridge: Cambridge University Press, 1992.

Trujillo, Ramón. Elementos de semántica linguiistica. Madrid: Cátedra, 1976.

Vucheva, Eugenia. "Tesis sobre la lingüística del hablar”. Pragmalingüística 20 (2012): 279-93. 